J. Gen. Appl. Microbiol.

Vol. 11, No. 2, 1965

\title{
REDUCTION SITES OF TELLURITE AND TETRAZOLIUM SALTS IN LISTERIA MONOC YTOGENES
}

\author{
TOMIO KAWATA and TERUTAKA INOUE \\ Department of Bacteriology, Tottori University \\ School of Medicine, Yonago, Japan \\ Received March 1, 1965
}

\begin{abstract}
During the past few years the intracytoplasmic membrane system has been demonstrated in thin sections of a number of bacteria and streptomycetes, as reviewed by Glauert(1) and Takagi and Kawata(2). Our previous electron microscopic observations(3) on the fine structure of Listeria monocytogenes revealed that the cytoplasm contained membranous structures having a variety of configurations. Edwards and $\operatorname{Stevens}(4,5)$, North (6) and GRUND(7) also studied the membrane system in the same organism. The membrane system has led to much speculation about its function; however, its biological activities have not yet been elucidated. Using thin sectioning and negative staining techniques, this work has been undertaken to examine the relationship between the intracytoplasmic membrane system and the reduction sites of potassium tellurite and of tetrazolium salts in $L$. monocytogenes.
\end{abstract}

\section{MATERIALS AND METHODS}

Organism and cultivation. L. monocytogenes 2318 (type $4 \mathrm{~b}$ ) was grown in GYB medium at $37^{\circ} \mathrm{C}$ with vigorous aeration as previously described (3). $\mathrm{K}_{2} \mathrm{TeO}_{3}$ or tetrazolium salts were added to the culture at the logarithmic growth phase (usually a 5 -hr culture) as the electron acceptors. Tetrazolium salts used were 2, 3, 5-triphenyl tetrazolium chloride (TTC) and 2, 2'-di-pnitrophenyl-5, 5'-diphenyl-3,3'-(3,3'-dimethoxy-4, 4'-biphenylene) ditetrazolium chloride (nitroblue tetrazolium, NBT).

Negative staining. The negative staining technique with phosphotungstate(8) has been applied successfully to elucidate the structure of viruses at the molecular level. According to Thornley and Horne's (9) procedure for electron microscopy of the bacterial surface, cells were negatively stained with phosphotungstate. After incubation with tellurite or tetrazolium salts, the cells were fixed by addition of formalin at a final concentration of $10 \%$ and then washed with distilled water. The cell suspension in distilled water was mixed with an equal volume of $2 \%$

1 This work was presented at the 10th Symposium of the Society of ElectronMicroscopy (Japan), Tokyo, November, 1963, and at the 37th General Meeting of the Japan Bacteriological Society, Nagasaki, April, 1964. 


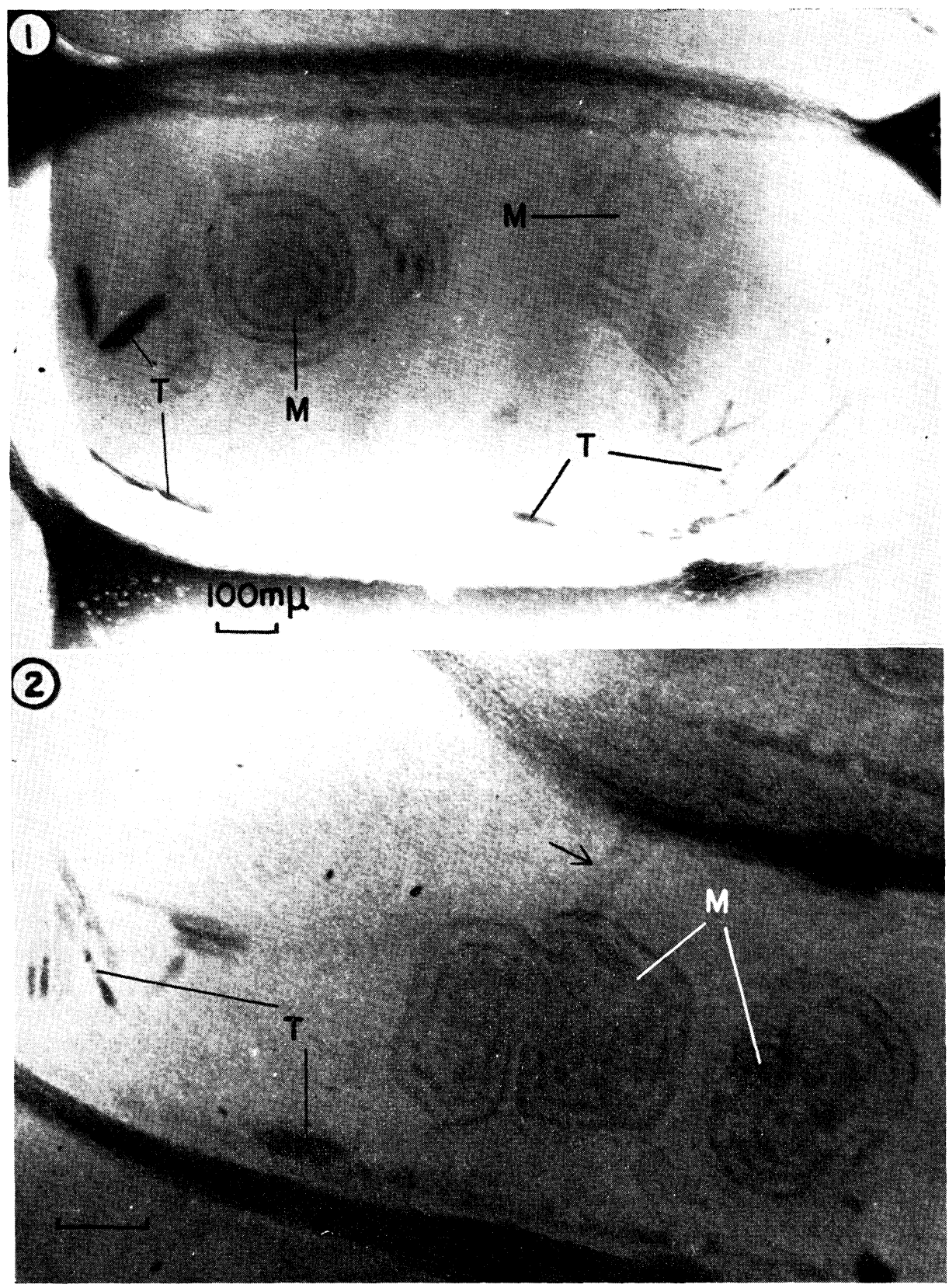

All the figures in this and the following plates are electron micrographs of $L$. monocytogenes strain 2318. The scale mark represents $100 \mathrm{~m} \mu$. The following abbreviations are used: $\mathrm{CW}$, cell wall; CM, cytoplasmic membrane; N, nuclear apparatus; M, intracytoplasmic membrane system; T, tellurium crystal; F, TTC. formazan deposit. 
phosphotungstic acid adjusted to $\mathrm{pH} 7.4$ with $1 \mathrm{~m} \mathrm{KOH.} \mathrm{A} \mathrm{drop} \mathrm{of} \mathrm{the}$ mixture was placed on a grid coated with collodion and carbon, and the excess fluid blotted from the edge of the grid with a tip of filter paper, leaving a thin film of liquid covering the grid.

Thin sectioning. Sections were prepared as previously mentioned(3). At given times, the cultures were prefixed by addition of buffered $\mathrm{OsO}_{4}$ at a final concentration of $0.1 \%$, and then immediately centrifuged to collect the cells. The cells were fixed with $1 \% \mathrm{OsO}_{4}$ in veronal-acetate buffer containing $0.68 \% \mathrm{NaCl}$ and $0.01 \mathrm{~m} \mathrm{CaCl}_{2}$ according to Kellenberger et al. (10), embedded in $2 \%$ agar, treated with $0.5 \%$ uranyl acetate, dehydrated in graded concentrations of ethyl alcohol, and finally embedded in n-butyl methacrylate monomer. Thin sections were cut on a Leitz FernándezMorán type ultramicrotome with a glass knife. Some sections were poststained with lead hydroxide according to WATson's method(11).

Electron microscopy. Specimens were studied with a Hitachi type HU-11 electron microscope with an accelerating voltage of $75 \mathrm{kv}$. Micrographs were taken at an initial magnification of 30,000 to 50,000 and enlarged 2 to 4 times in printing.

\section{RESULTS}

\section{Reduction of potassium tellurite}

Reduction of $\mathrm{K}_{2} \mathrm{TeO}_{3}$ required a longer time than that of tetrazolium salts, 1-2 hours being necessary for appreciable tellurium deposit. $\mathrm{K}_{2} \mathrm{TeO}_{3}$ was added to the aerated culture at the logarithmic phase of growth to give a final concentration of $0.01 \%$. The culture was then kept at $37^{\circ} \mathrm{C}$ without aeration for $2 \mathrm{hr}$. After fixation with formalin, the whole cells were negatively stained with phosphotungstate. As shown in Figs. 1 and 2, lamellar and vesicular structures of the same morphology as the intracytoplasmic membrane system seen in thin sections (3) were distinctly visible in the whole cells. In Fig. 2 a lamellar structure appeared to connect with, probably, the cytoplasmic membrane through a tubule, as indicated by an arrow. Reduced tellurite was demonstrated as an electron-dense needle-like crystal within the cell. The tellurium crystals were often situated around the periphery of the cell, but they did not usually deposit on the membranous structure. This significant feature was also recognized on thin sections of the cells incubated with tellurite. Figures 3 and 4 demonstrated that the sites of tellurium deposition were mainly on or near the inner layer of the cytoplasmic membrane. Occasionlly, the crystals

Figs. 1 and 2. Negatively stained cells after incubation with $0.01 \% \mathrm{~K}_{2} \mathrm{TeO}_{3}$ for $2 \mathrm{hr}$. Tellurium crystals $(\mathrm{T})$ are mainly deposited around the periphery of the cytoplasm, but not on the membranous organelle (M). As indicated by an arrow in Fig. 2, a large lamellar structure appears to be connected with the cell periphery through a tubule. 

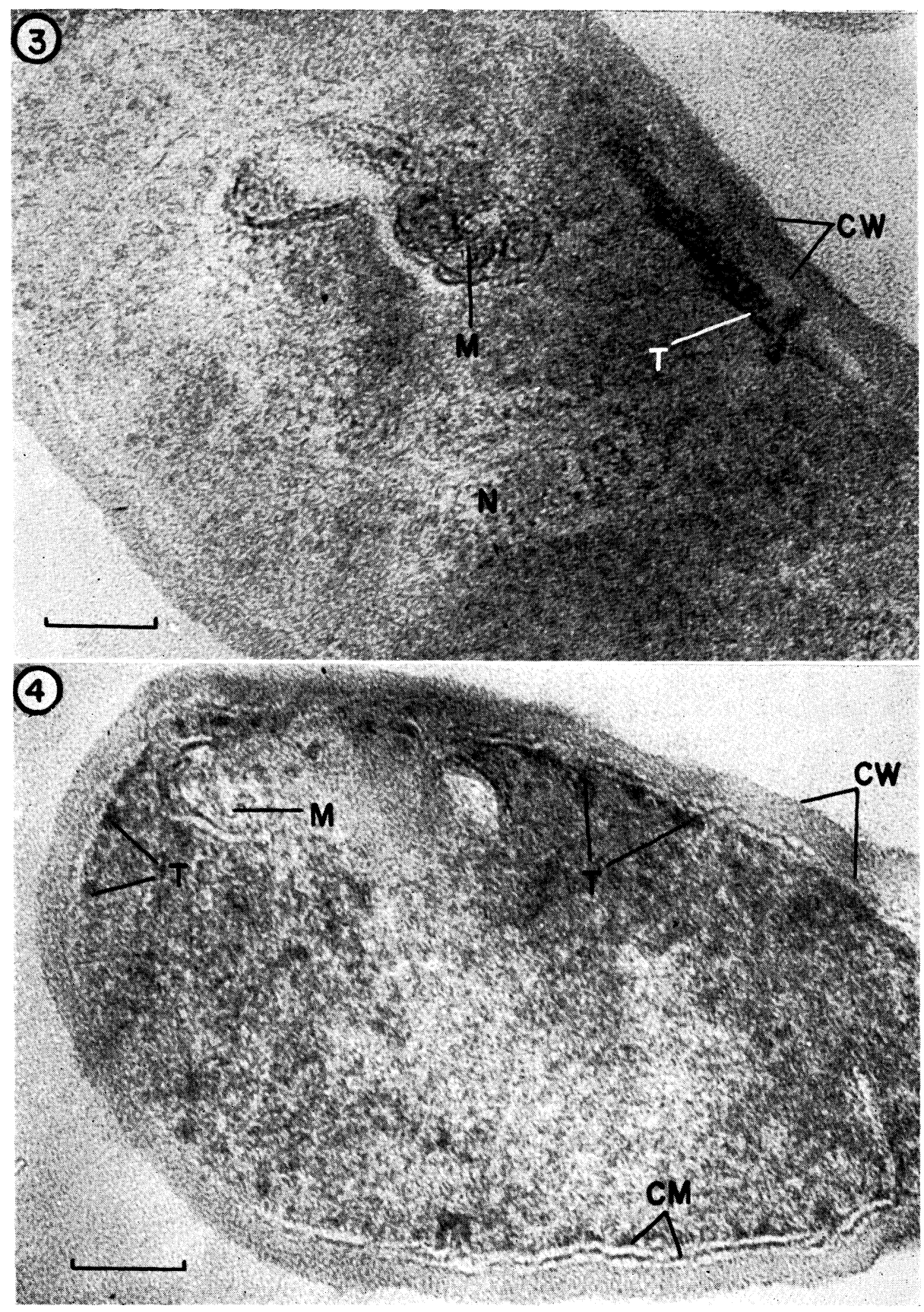

Figs. 3 and 4 . Sections of cells after incubation with $0.01 \% \quad \mathrm{~K}_{2} \mathrm{TeO}_{3}$ for $2 \mathrm{hr}$. Tellurium crystals ( $\mathrm{T}$ ) are mainly deposited on or near the inner layer of the cytoplasmic membrane $(\mathrm{CM})$. 

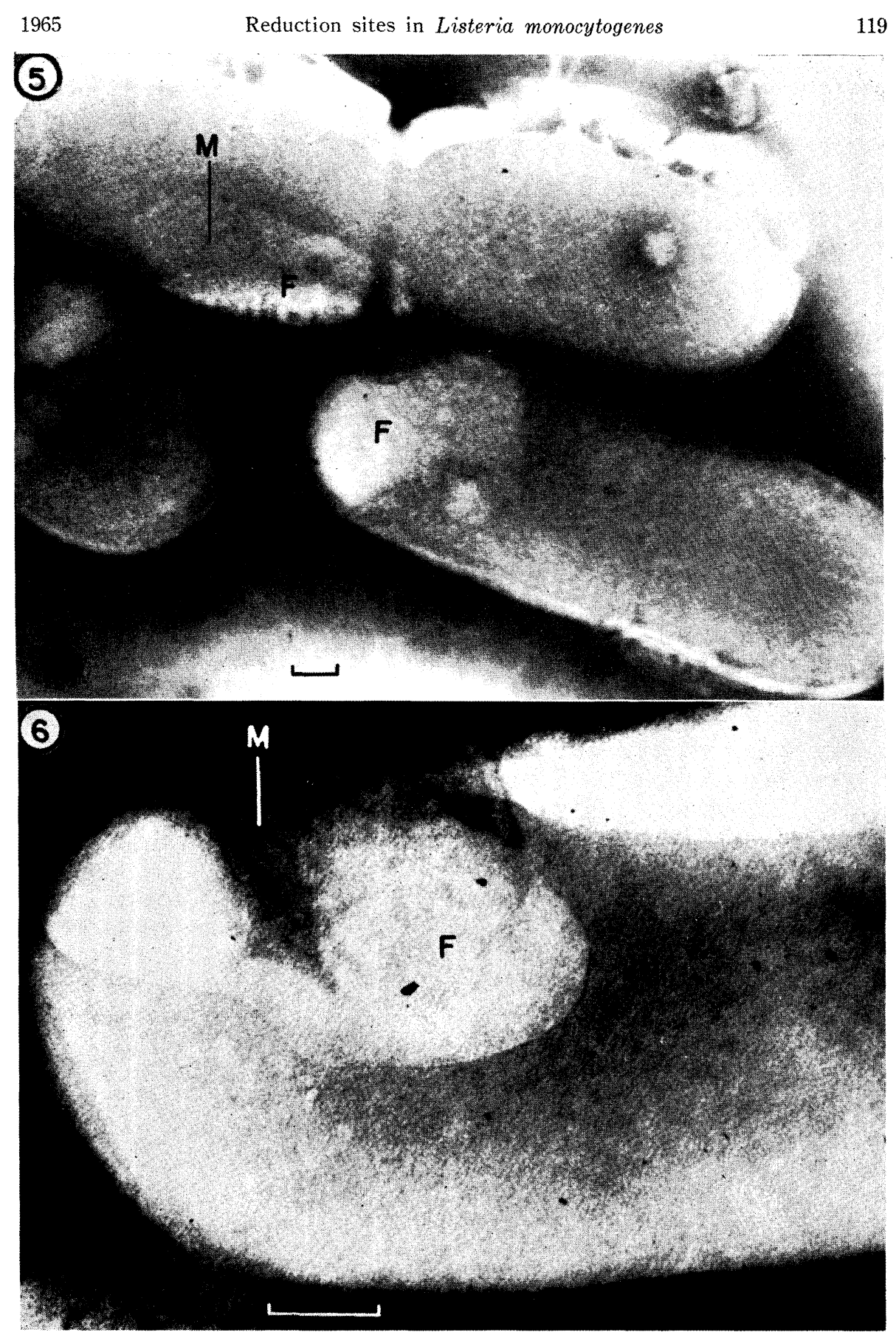

Figs. 5 and 6 . Negatively stained cells after incubation with $0.05 \%$ TTC for 5 min. TTC-formazan deposits (F) can be seen as electron transparent areas. The formazan deposits appear to be laid on the intracytoplasmic membrane system (M). 
were found in the central region of the cytoplasm. It was very noticeable that there was no morphological relationship between the intracytoplasmic membrane system and the reduction of potassium tellurite.

Reduction of tetrazolium salts

Tetrazolium salts were rapidly reduced to formazans in the actively growing culture. Red formazan granules appeared in the cells about $2 \mathrm{~min}$ after addition of TTC. After incubation with $0.05 \%$ TTC for $5 \mathrm{~min}$, the cells were fixed with formalin, and then negatively stained with phosphotungstate. The resultant TTC-formazan was shown as a lighter mass because phosphotungstate could not penetrate into the formazan. Figures 5 and 6 revealed that the TTC-formazan appeared to be located closely on the intracytoplasmic membrane system.

The TTC-formazan in the cells was readily dissolved in ethyl alcohol during the dehydration procedure for sectioning. Thus, the site of TTCformazan deposition was seen as an electron-transparent area in sections of the cells. Figures 7 and 8 demonstrated sections of the cells incubated with $0.05 \%$ TTC for $2 \mathrm{~min}$. A rectangular or round transparent region appeared to correspond to the location of the TTC-formazan deposit. This region was usually surrounded by 2 or 3 dense layers, probably parts of the intracytoplasmic membrane system. The formazan deposits gradually increased in volume as the incubation period was prolonged. Large formazan crystals were seen to be in contact with the lamellar structure in the nuclear region (Figs. 9 and 10). In Fig. 10 a growing formazan crystal ruptured a part of the cell wall. These formazan crystals also were partially surrounded by 2 or 3 dense layers as shown by arrows. After incubation with TTC for $8 \mathrm{~min}$, the formazan deposits developed into large irregular crystal-shaped forms as shown in Figs. 11 and 12. It was conspicuous that the large formazan crystals were still surrounded by dense layers possibly corresponding to parts of the intracytoplasmic membrane system. These findings strongly suggest that the TTC-reduction may occur on or in the membrane system but not on the cytoplasmic membrane. A large complex membranous structure was seen to be adjacent to a large formazan crystal in Fig. 11.

In contrast to TTC-formazan, NBT-formazan scarcely dissolved in ethyl alcohol during the dehydration procedure. Therefore, the site of the NBTformazan deposition could not be illustrated as a tranparent area as that of the TTC-formazan deposition. Figures 13 and 14 demonstrated sections of the cells incubated with $0.01 \% \mathrm{NBT}$ for $2 \mathrm{~min}$ (Fig. 13) and for $5 \mathrm{~min}$ (Fig. 14). There were no transparent crystal-like regions as observed in sections of the TTC-treated cells, but transparent zones were shown between membranous components of the intracytoplasmic membrane system. The membrane system appeared to become more or less disorganized. 

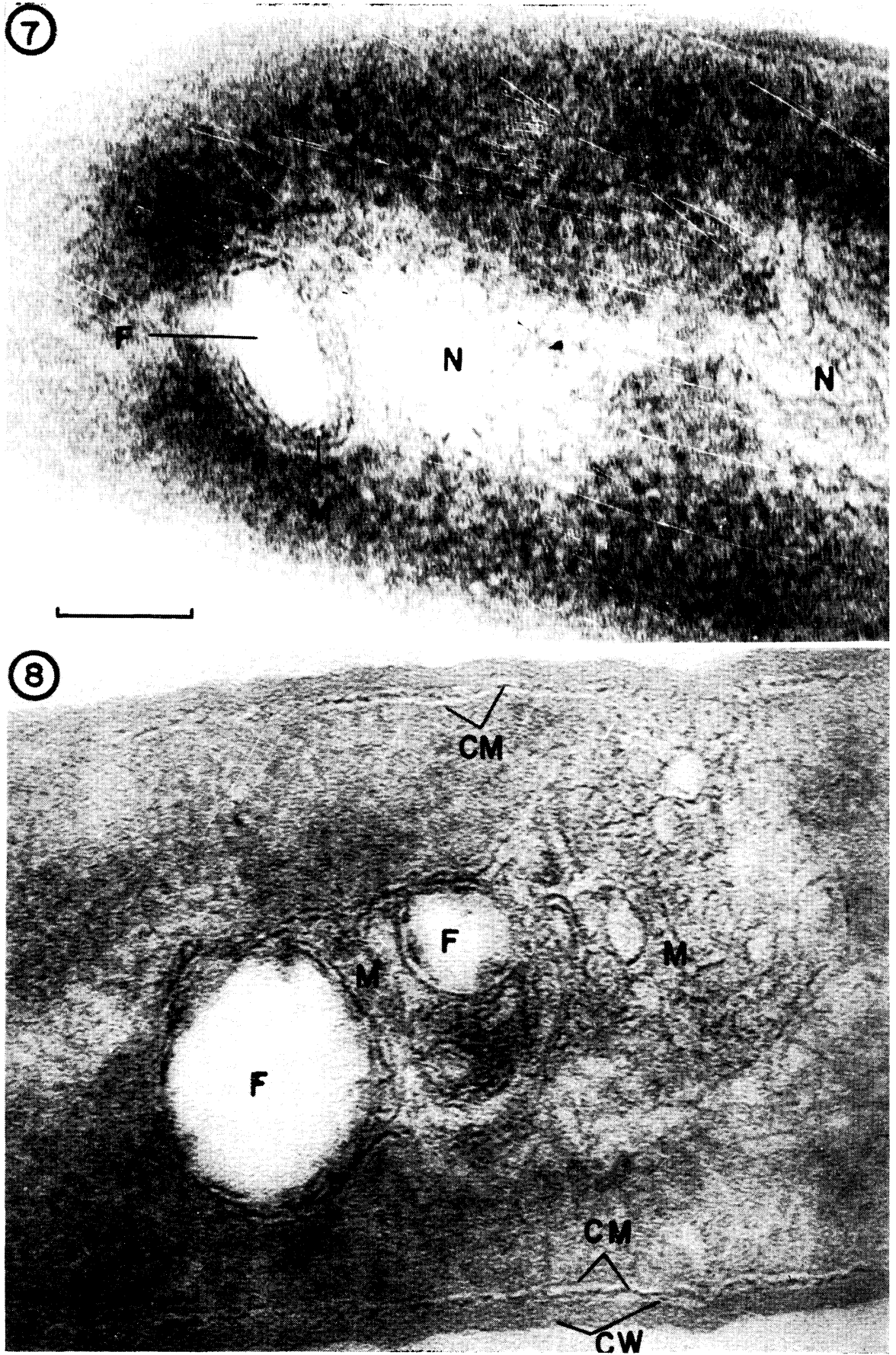

Figs. 7 and 8 . Sections of cells after incubation with $0.05 \%$ TTC for 2 min. A rectangular (Fig. 7) or round (Fig. 8) transparent area (F) corresponding to the formazan deposit is surrounded by dense layers. 


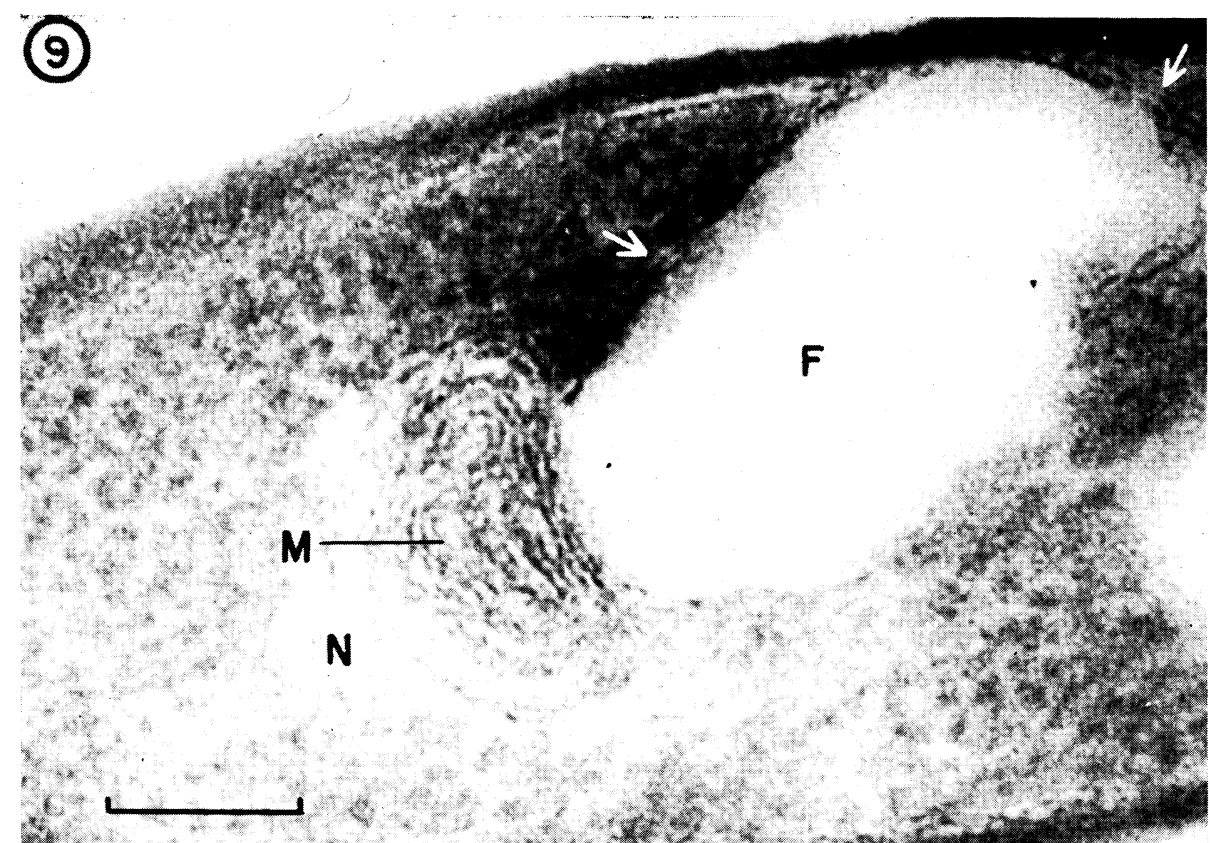

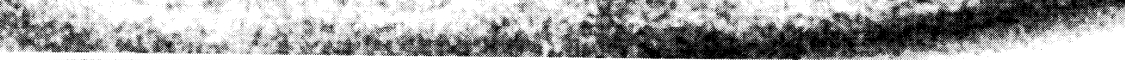

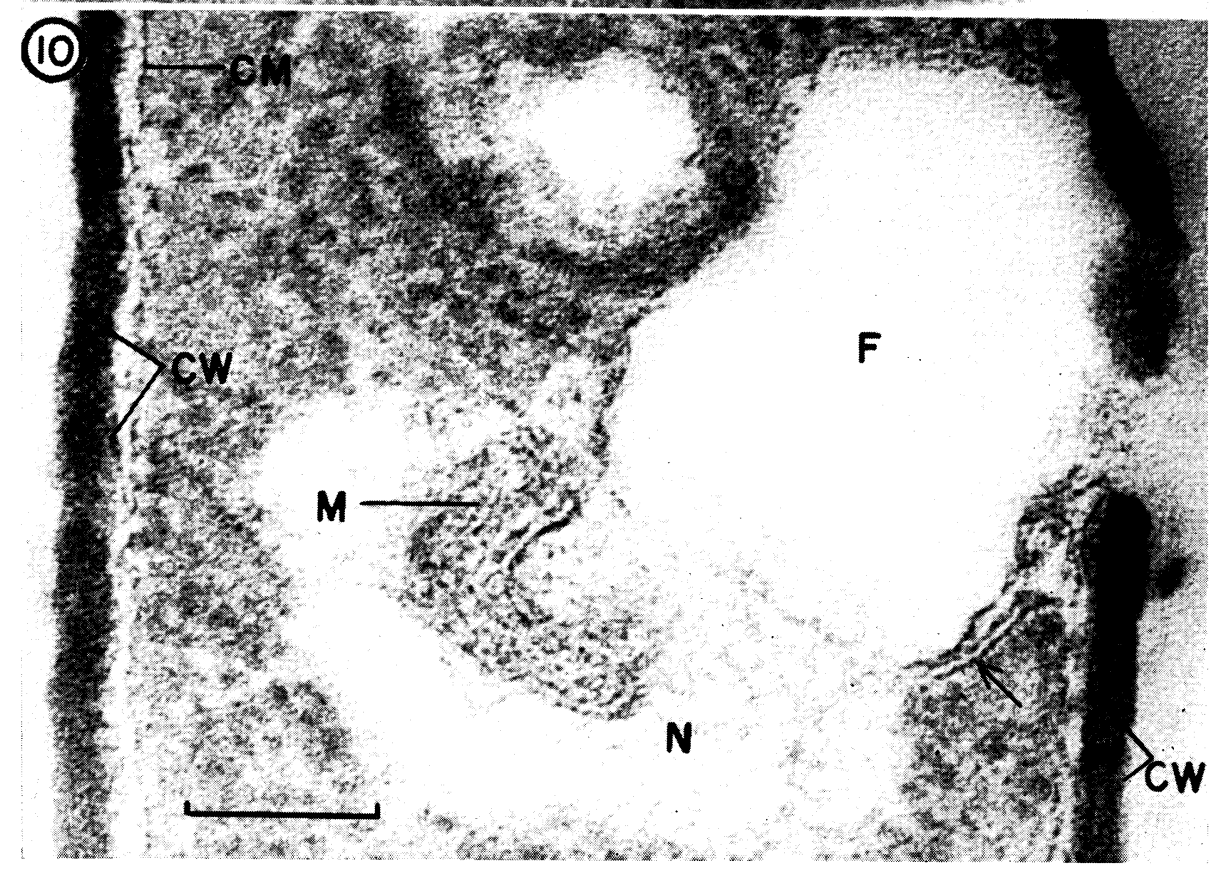

Figs. 9 and 10. Sections of cells after incubation with $0.05 \%$ TTC for $4 \mathrm{~min}$. Stained with $\mathrm{Pb}(\mathrm{OH})_{2}$. As indicated by arrows in both figures, large formazan deposits (F) are partially enclosed by 2 or 3 dense layers, probably corresponding to parts of the membrane system, and they are in contact with the membranous structure (M) within the nuclear region (N). In Fig. 10 a large formazan deposit is breaking up the cell wall (CW). 

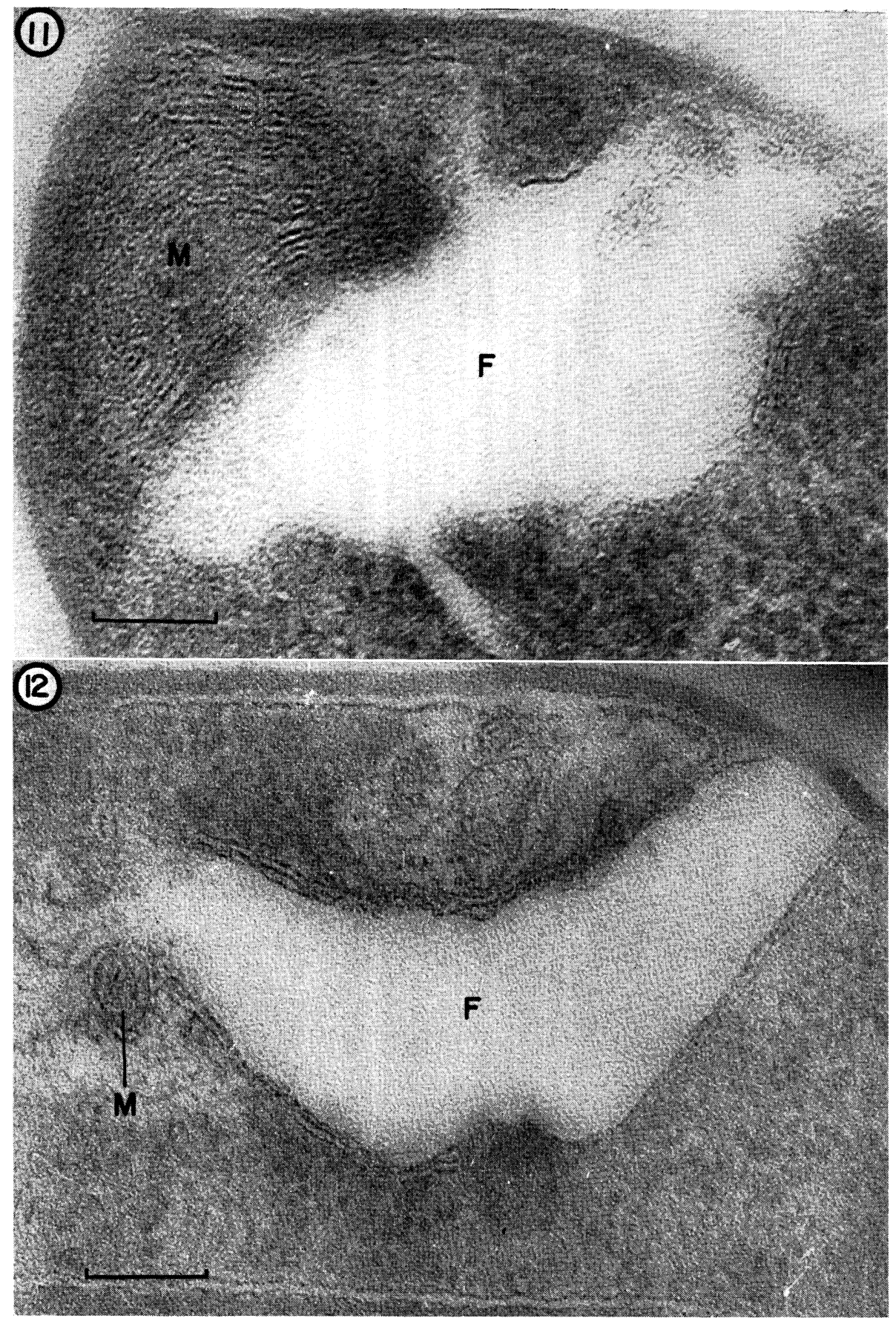

Figs. 11 and 12. Sections of cells after incubation with $0.05 \%$ TTC for $8 \mathrm{~min}$. Formazan deposits develop into large irregular crystals and are still surrounded by dense layers. A large concentric membranous structure (M) is adjacent to the formazan deposit in Fig. 11. 


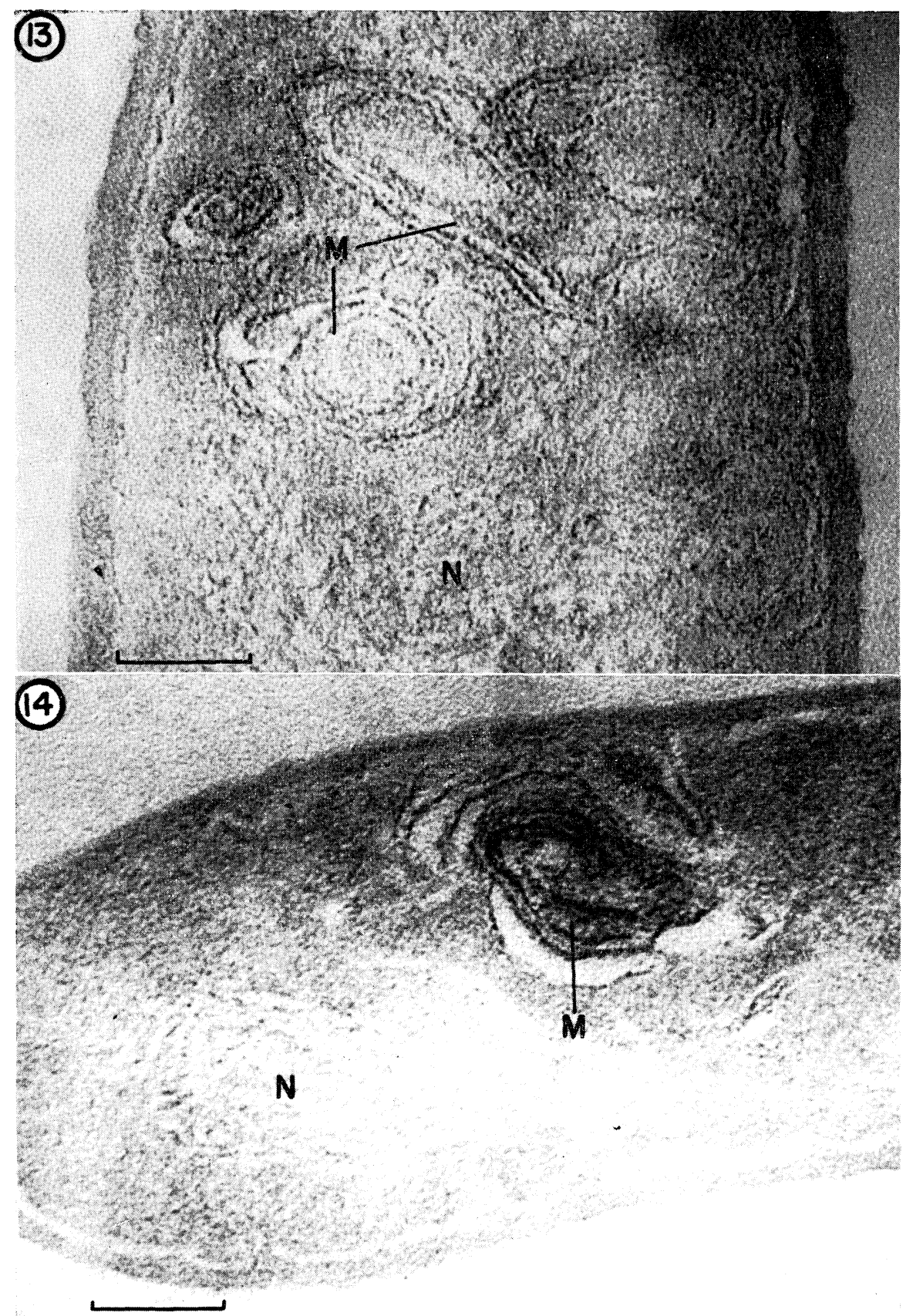

Figs. 13 and 14. Sections of cells after incubation with $0.01 \%$ NBT for $2 \mathrm{~min}$ (Fig. 13) and for 5 min (Fig. 14). Transparent zones are visible between membranous components of the membrane system (M), but there are no crystal-like transparent regions as demonstrated in sections of TTC-treated cells. 


\section{DISCUSSION}

In higher organisms the mitochondria are well known to be the centers which are responsible for the respiration of cells. However, in bacteria the location of the respiratory enzyme systems comparable to the mitochondria has not yet been established. Recent electron microscopy of bacteria revealed the presence of an intracytoplasmic membrane system in a variety of bacteria. Based on analogies of the structures of the bacterial membrane system and the mitochondria, this membrane system was first considered to be equivalent to the mitochondria of higher organisms by Shinohara et al. (12) and Giesbrecht (13); however, it seems precocious to identify the membrane system found in bacteria with the mitochondria. The relationship between the enzymatic localization and the membrane system has been extensively investigated by many workers with electron microscopy on bacterial cells treated with potassium tellurite or tetrazolium salts as indicators for respiratory activities. However, the results obtained from one species of bacteria has not always coincided with those obtained from another species. Thus, the true nature and the biological functions of the bacterial membrane systems have not yet been solved.

Potassium tellurite, if reduced by living cells, is deposited as tellurium in the form of fine needle-shaped crystals and as granular deposits of tellurium oxide. MUdD et al. (14) observed in unsectioned mycobacteria that the reduction of tellurite occurred throughout the cytoplasm and, in particular, in circumscribed organelles functionally equivalent to the mitochondria. Later, BRIEGER (15) showed in sections of human tubercle bacilli that the tellurium needles were distributed throughout the cytoplasm but not associated with the membrane systems. Before this observation, TeraI et al. (16) extracted tellurite-reducing enzyme from the soluble fraction, but not from the particulate fraction, of Mycobacterium avium and referred to it as tellurite reductase. On the other hand, Nermut (17) observed in Proteus vulgaris under the light microscope that tellurite was reduced either directly in the cytoplasmic membrane or in its immediate environment, most probably in the lipid granules. Furthermore, Mudd et al. (18) demonstrated in sections of Bacillus megaterium that tellurium crystals were found at sites near the periphery of the cytoplasm, and they suggested that the sites of reduction were in or in close association with the plasma membrane. Suganuma (19) also described that sections of Staphylococcus aureus grown in the presence of potassium tellurite showed reduced tellurite lying in the bays formed by the infolding of the plasma membrane. TAKAGI et al. (20) found in sections of Fusobacterium polymorphum that the tellurium crystals were deposited in the immediate environment of the cytoplasmic membrane and the intracytoplasmic membrane system. Recently, VAN ITERsoN and LeENe (21) observed in Bacillus subtilis that the density of the membranous organelle became higher than that of the plasma membrane after 
treatment with tellurite, and explained this phenomenon was due to deposition of the reduced tellurite and, consequently, tellurite reduction occurred on or in the membranes of particular organelles, but not on the plasma membrane. However, we cannot agree with their explanation because the intracytoplasmic membrane systems are frequently more heavily stained and clearly outlined in the cells where the cytoplasmic membrane is hardly or not at all visible, and tellurium crystals can be seen often at the cell periphery but not on the membranous organelles in their micrographs. Furthermore, they (22) stated regarding sections of $P$. vulgaris that reduced tellurite was found to be deposited in bodies contiguous with the plasma membrane but not in the plasma membrane to any important degree. Thus, the reduction sites of tellurite, which appear to differ with different species of bacteria, have become confused. However, the evidence obtained here from negatively stained and sectioned cells of $L$. monocytogenes strongly suggests that the dehydrogenase system causing the reduction of tellurite may be localized principally on or near the inner layer of the cytoplasmic membrane, but not in the intracytoplasmic membrane system. The present experiment supports Hughes's concept (23) that the cytoplasmic membrane would be the main site of the respiratory enzyme chain.

MudD and his colleagues $(24,25)$ described in earlier reports on the sites of bacterial oxidation-reduction that granules visible by light microscopy after staining with tetrazolium salts, Nadi reagent, or Janus green B, were presumed to be the mitochondria or at least the mitochondrial equivalent. Using TTC as a redox indicator, NikLowitz (26) first showed vacuoles caused by dissolution of the TTC-formazans in sections of Escherichia coli and he concluded that these redox centers might correspond to the mitochondrial equivalents. Later, VANDERwinkel and MurRay (27), applying TTC to living bacteria, demonstrated in sections that no defined organelles were present as reduction sites of tetrazolium salt in $E$. coli; whereas the mesosomes which were introduced by Fitz-JAMES (28) to represent the intracytoplasmic membrane system of Bacillus group were sites of the oxido-reduction system in B. subtilis and Spirillum serpens. Furthermore, TAKagI et al. (29) observed in sections of $F$. polymorphum that NBT-formazans were deposited very close to the cytoplasmic membrane and the intracytoplasmic membrane system. Nermut and RÝc (30) also showed in sections of P. vulgaris that NBT-formazan deposits were situated mainly in the immediate vicinity of the cytoplasmic membrane and they concluded that the cytoplasmic membrane might play a significant part in oxidation-reduction processes. On the other hand, Suganuma (19) used the MTT (3-(4, 5-dimethylthiazolyl-)-2, 5-diphenyl tetrazolium bromide) cobalt method of Pearse (31) for demonstrating the localization of dehydrogenase systems of $S$. aureus, but unfortunately he could not find details of the regions of the formazan deposits. In our experiment, TTC-formazan was completely dissolved in 
ethyl alcohol during the dehydration procedure, whereas NBT-formazan was hardly dissolved. Because of this, the site of TTC-formazan deposit could be more easily demonstrated as a transparent crystal-like area in sections than that of NBT-formazan deposit. In cells of $L$. monocytogenes the sites of TTC-reduction are mainly localized in or on the intracytoplasmic membrane system. This fact, similar to findings of VANDERwINkEL and MURRAY (27) with $B$. subtilis and S. serpens, strongly suggests that the intracytoplasmic membrane system may play an important role in the respiratory enzyme chain. However, it should be noted that the reduction of tetrazolium salts and potassium tellurite occurred at different places in the cell. From these evidences it seems likely that the intracytoplasmic membrane system, possibly derived from the cytoplasmic membrane, may differ functionally from the latter in the oxido-reduction systems of bacterial cells.

\section{SUMMARY}

Employing negative staining and thin sectioning techniques, the reduction sites of potassium tellurite and of tetrazolium salts in $L$. monocytogenes were revealed by electron microscopy. When the cells were negatively stained with phosphotungstate, the intracytoplasmic membrane system composed of complex lamellar and vesicular structures was distinctly demonstrated. Potassium tellurite was mainly reduced to metallic tellurium crystal on and/or near the inner layer of the cytoplasmic membrane but not in the intracytoplasmic membrane system.

Triphenyl tetrazolium chloride (TTC) was reduced to TTC-formazan on or in the intracytoplasmic membrane system. As the TTC-formazan was dissolved in ethanol during the dehydration, the site of the formazan deposit appeared as a transparent crystal-like area surrounded by parts of the membrane system in sections of the cells. These findings strongly suggest that the tellurite-reduction system may principally be located on or near the inner layer of the cytoplasmic membrane, whereas the dehydrogenase system of the tetrazolium salt may be associated mainly with the intracytoplasmic membrane system.

\section{REFERENCES}

(1) A. M. Glauert: Brit. Med. Bull., 18, 245 (1962).

(2) A. Takagi and T. Kawata: Symposium on Structure of Microorganisms, p. 1, Edited by Inst. Appl. Microbiol., Tokyo (1962).

(3) T. Kawata: J. Gen. Appl. Microbiol., 9, 1 (1963).

(4) M. R. Edwards: Second Symposium on Listeric Infection, Edited by M. L. Gray, Montana State College, Bozeman (1963).

(5) M. R. Edwards and R. W. Stevens: J. Bacteriol., 86, 414 (1963).

(6) R. J. NoRTh: J. Ultrastructure Res., 9, 187 (1963). 
(7) S. Grund: Z Zbl. Bakt. I. Orig., 189, 405 (1963).

(8) S. BrenNer and R. W. Horne: Biochim. Biophys. Acta, 34, 103 (1959).

(9) M. J. Thornley and R. W. Horne: J. Gen. Microbiol., 28, 51 (1962).

(10) E. Kellenberger, A. Ryter and J. Séchaud: J. Biophys. Biochem. Cytoı., 4, 671 (1958).

(11) M. L. Watson: J. Biophys. Biochem. Cytol., 4, 727 (1958).

(12) C. Shinohara, K. FukUShI and J. Suzuki: J. Bacteriol., 74. 413 (1957).

(13) P. GieSBRECHT: Z Zbl. Bakt. I. Orig., 179, 538 (1960).

(14) S. Mudd, K. Takeya and H. J. Henderson: J. Bacteriol., 72, 767 (1956).

(15) E. M. BRIEGER: Structure and Ultrastructure of Microorganisms, Academic Press, p. 211, New York (1963).

(16) T. Terai. T. Kamahora and Y. Yamamura: J. Bacteriol., 75, 535 (1958).

(17) M. V. Nermut: Zbl. Bakt. I. Orig. 178, 348 (1960).

(18) S. Mudd, T. Kawata, J. I. Payne, T. Sall and A. Takagi: Nature, 189, 79 (1961).

(19) A. Suganuma: J. Infect. Dis., 111, 8 (1962).

(20) A. Takagi, K. Ueyama and M. Ueda: Yonago Acta Medica, 7, 18 (1963).

(21) W. van Iterson and W. Leene: J. Cell Bioi., 20, 361 (1964).

(22) W. van Iterson and W. Leene: J. Cell Biol., 20, 377 (1964).

(23) D. E. Hughes: J. Gen. Microbiol., 29, 39 (1962).

(24) S. Mudd, L. C. Winterscheid, E. Delamater and H. J. Henderson: $J$ Bacteriol., 62, 459 (1951).

(25) S. Mudd: Ann. Rev. Microbiol., 8, 1 (1954).

(26) W. NikLowitz: Z Zbl. Bakt. I. Orig., 173, 12 (1958).

(27) E. VANDERWINKeL and R. G. E. MURRAY: J. Ultrastructure Res., 7, 185 (1962).

(28) P. C. Fitz-James: J. Biophys. Biochem. Cytol., 8, 507 (1960).

(29) A. Takagi, K. Ueyama and M. Ueda: J. Gen. Appl. Microbiol., 9, 287 (1963).

(30) M. V. Nermut and M. V. RÝc: Folia Microbiol., 9, 16 (1964).

(31) A. G. E. Pearse: J. Histochem. Cytochem., 5, 515 (1957). 